九州大学学術情報リポジトリ

Kyushu University Institutional Repository

\title{
Diversity of Distributed Music and Modern Telecommunication Technologies: A Network Perspective
}

\author{
Teramoto, Shinto \\ Faculty of Law, Kyushu University: Professor | Faculty of Law, University of Indonesia: \\ Assistant Professor I Faculty of Law, Kyushu University: Assistant Professor \\ Larasati, Desrezka Gunti \\ Faculty of Law, Kyushu University: Assistant Professor | Faculty of Law, Kyushu University: \\ Professor | Faculty of Law, University of Indonesia: Assistant Professor \\ Jurčys, Paulius \\ Faculty of Law, Kyushu University: Assistant Professor | Faculty of Law, Kyushu University: \\ Professor | Faculty of Law, University of Indonesia: Assistant Professor
}

http://hdl. handle. net/2324/25387

出版情報 : 2012-11-13. Creative Media Days - Workshop Innovation \& Diversity in the Media Economy, IBBT-SMIT, Vrije Universiteit Brussel

バージョン：

権利関係 : 


\title{
DIVERSITY OF DISTRIBUTED MUSIC AND MODERN TELECOMMUNICATION TECHNOLOGIES: A NETWORK PERSPECTIVE
}

\author{
Shinto Teramoto* \\ Desrezka Larasati* \\ Paulius Jurčys ${ }^{* * *}$
}

TABLE OF CONTENTS

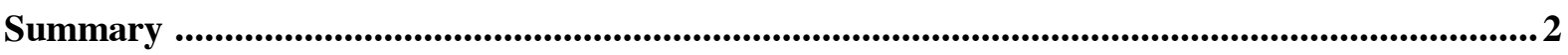

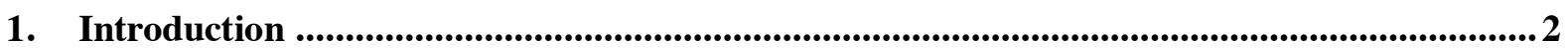

2. Overview of the Conventional Music Distribution System ..................................................5

2.1. Conventional Model of Music Distribution ..............................................................6

2.2. Limited Diversity of Distributed Music under Conventional Model....................................8

3. Distribution and Dissemination of Music Affected by the Internet and Cloud Computing Technology ......................................................................................................................................... 13

3.1. Music Distribution: Short Distance and Any-to-Any ............................................................. 14

3.2. Modelling the Remarkable Reduce of Distance ....................................................................... 16

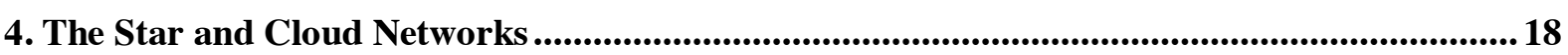

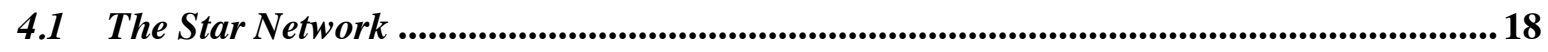

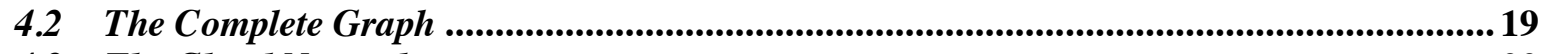

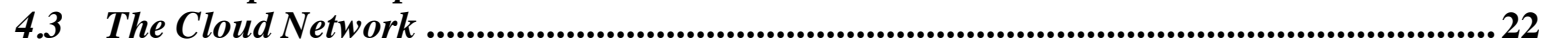

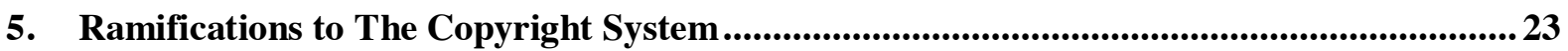

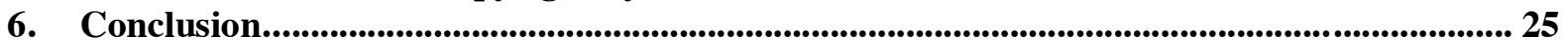

* Professor of law at Kyushu University, Faculty of Law (Japan) where he teaches intellectual property law. He is also a practicing lawyer specializing in venture capital finance and intellectual property law.

** Desrezka Gunti Larasati is a LL.M. graduate at Kyushu University, Faculty of Law. She is a researcher at the University of Indonesia Faculty of Law study group on law and technology.

${ }^{* * *}$ Assistant professor at Kyushu University, Faculty of Law, LL.M., LL.D. 


\section{Summary}

This paper adresses the debates surrounding the impact of the Internet and cloud computing technology to the activities in music industry, especially at the stage of music distribution and dissemination. Building upon the realistic observations concerning the 'conventional' as well as innovative music distribution business models, this paper provides for simulations and analysis using the social network approach. These simulations are used in order to assess how the goal of diversity of music could be achieved in innovative communication networks. The paper shows the essential role of intermediaries that are involved in facilitation of the diversity of music, innovation, as well as the system of music distribution and dissemination. At the final Chapter, this paper introduces some considerations concerning copyright as a legal tool used in constructing the music distribution and dissemination system.

\section{Introduction}

Music publishing is aimed at making music available to the public. ${ }^{1}$ In making such music available, music business involves certain stages that could be categorized into ${ }^{2}$ : (a) the stage of creation ${ }^{3}$, (b) the stage of distribution or dissemination of music ${ }^{4}$, and (c) the stage of consumption. ${ }^{5}$ In each stage, the actors ${ }^{6}$ involved, namely artists, record labels, distributors,

${ }^{1}$ Bobby Borg, The Musician's Handbook - A Practical Guide to Understanding the Music Business (New York: Billboard Books, 2003); Helen Gammons, The Art of Music Publishing (London: Elsevier Ltd, 2011); Richard E. Caves, Contracts Between Art and Commerce (Cambridge: Harvard University Press, 2000); Donald S. Passman, All You Need to Know About the Music Business - Revised and Updated (New York: Free Press, 2009).

2 Similarly, Andrew Leyshon categorizes four models of 'musical networks'; namely, (1) the network of creativity, where music is created, performed, and recorded; (2) the network of reproduction, (3) the network of distribution, and (4) the network of consumption (Patrik Wikstrom, The Music Industry, Digital Media and Society Series (Cambridge: Polity, 2009), 49-50).

${ }^{3}$ In the creation stage, besides making of the composition or arrangement of the songs, it includes also the process of recording, in which several functions could be found encompassing studio musicians, sound engineers, and record studios. The record labels make investment in form of 'recording funds' which consist of musicians' and producers' advance, as well as funding for the making of the songs or album. The original songs or albums produced in the phonogram will be the 'master', from which copies are being made. (Donald S. Passman, supra note 2, at 79-80).,

${ }^{4}$ In general, the distribution activities may include restoring the stocks of recorded music physical copies, shipping to suppliers, manufacturing of physical albums, as well as handling the fulfillment and delivery of orders from stores and online retailers. The major record labels, who seek musicians that commercially viable and have greater potential of quick returns on the investments, are usually parts of larger corporations that run a system of distribution channels, regional offices, international divisions, and other music business, such as music publishing (Bobby Borg, at 174; Donald S. Passman, supra note 2). In this stage, music is also being promoted with the supports from publishers and broadcasting organizations, so that the music could reach the consumers.

${ }^{5}$ As providing channels for music consumption, under the conventional model, which are mainly based on physical products, consumers can access music products through the music stores. They could also access and enjoy the music through broadcasts by TV and radio, as well as attending musicians' live concerts or performances organized by promoters or live agents.

${ }^{6}$ One of the key notions of the social network approach and the sociograph theory is that the actors in music industry could be represented as 'points' to which they have 'lines' (or, 'arc') toward each other, and so channels or connections could be recognized between them. Christina Prell refers such parties involved in the networks as 'actors,' or 'nodes' if it is derived from graphs. One of the theorists, namely Jacob Moreno, considers that the mapping of these structures into a sociogram allowed a researcher to visualize the channels 
and broadcasting organizations, engage in deals with each other aiming at creating and recording the music, as well as reproduction, distribution and dissemination of music to consumers. These transactions between the actors are mainly directed towards the facilitation of music distribution to consumers who access, acquire, and enjoy music. In making the music available and accessible the actors involved choose and develop the media and channels they use; these actors also determine in what form the music shall be presented to the audience?

The emergence of the Internet and cloud computing technologies have changed the whole structure of the conventional music distribution networks ${ }^{8}$ by way of providing alternative platforms ${ }^{9}$ for the distribution and access of music. In the light of this phenomenon, the importance of physical music distribution has been diminishing, while the Internet and cloudbased media offer alternative channels for swift and qualitative music access and distribution. The Internet and cloud computing have lowered the barriers to enter the music distribution market and provides for essentially novel structure of music distribution. Namely, the conventional modes of physical music distribution made it possible for several actors who are also proprietors of exclusive copyrights (such as record labels or distributors) to monopolize the channels of music access. Such competition-related problems diminish in the Internet and cloud-based environment where the flow and access to music is considerably easier: each user can quickly share, access, or even acquire (i.e. download) digital music files while conventional music industry actors have much less control over the music flow.

This paper focuses on business of distribution and dissemination of music. In particular, we aim to analyse the structure of conventional music distribution models and investigate how the Internet and cloud computing technology have affected these music business models. We juxtapose two situations: (a) the conventional music distribution system where monopolies (or, oligopolies) of certain actors exist and (b) music distribution model which is based on the Internet and the cloud computing technologies where the actual competition between the music business actors exists. Furthermore, we aim to explore the implications of the Internet and cloud computing to the promotion of the diversity of distributed music.

through which, for example, information could flow from one person to another and through which one individuals could influence another. The construction of sociograms allowed researchers to identify leaders and isolated individuals, to uncover asymmetry and reciprocity, and to map chains of connection. One example of this principal sociometric concepts was the sociometric 'star,' in which the actor becomes the recipient of numerous and frequent choices from others and who, then, held a position of great popularity and leadership. (See John Scott, Social Network Analysis: A Handbook (London: Sage, 2nd ed., 2000), at 3-10; and Christina Prell, Social Network Analysis: History, Theory, and Methodology (Los Angeles: Sage, 2012), at 8).

${ }^{7}$ For example, the record labels could help promote the artists and the music through constructing broadcast deals with TV or radio companies, through which the music could be airplayed, or when the artists get the spotlight of being interviewed, as well as perform live their music during such TV or radio shows. Other channel could be in form of live concerts or performances at entertainment places, such as cafe or clubs. The Internet and technology have facilitated music copies to be downloaded or streamed through online sites. (See Patrik Wikstrom supra note 2, at 49-60).

${ }^{8}$ The conventional music distribution networks mainly based on physicial products with exclusive gatekeepers and oligopolistic market, in which they create 'artificial scarcity' of music distributed and disseminated to the consumers. In this case, they have strong controls and could exclude distribution and dissemination of music by other actors who have not been granted the (copyrights) authorization s by the right holders. (See William Patry, How to Fix Copyright (New York: Oxford University Press, 2011), 16-17; and Patrik Wikstrom supra note 3, at 5-6).

${ }^{9}$ For instance, the emerging online music sites, namely Spotify, from which consumers can subscribe for music streaming, Reverbnation, which acts as bridge for artists/musicians to share and promote their music, as well as build fan base, and Bandcamp. which acts as platform for consumers to directly purchase the music from the artists/musicians. 
By using the approach of network analysis, we deem music distribution system as a communication network where the actors in the music industry interact with one other. The identification of the channels or connections between various actors also helps to recognise the flows of music products between them. Such connections between the actors who operate mainly with an objective of making the music available to the market could be characterised in terms of 'dependency' and 'reciprocity' and each of them has its own essential role and functions. To identify these networks and relations between such actors, we have to observe the reality and practice in music business, and establish a rather simple model which enables us to conduct the analysis.

Like any other commercial activity in the creative industry, music business has always been a risky game: the infinite variety ${ }^{10}$ of music produced, the heterogeneous consumer demand and taste of music suggest that nobody knows ${ }^{11}$ whether a music distributed in the market could become a 'hit' and gain popularity. Yet, investments and funding are necessary to bring the music to the market. Therefore, copyright provides for a legal scheme of exclusive rights that are granted to actors for the publication and reproduction of music. Copyright also helps to retain their control over the channels and paths ${ }^{12}$ of music access and distribution. The exclusivity and authorizations of rights framed under the copyright regime provides for incentives to engage in a risky music business in which the actors are able to control the exploitation and distribution of music by utilizing and enforcing such exclusive rights. ${ }^{13}$ In other words, copyright provides for a possibility to construct exclusive paths to distribute and disseminate music, which also means that the respective actors can secure the economic income from the music products.

However, as mentioned earlier, the Internet and cloud computing have allowed easy flows and distribution of music through networking between the consumers. This has been considered as threat, for example by the record labels, publishers, or music distributors, to their exclusive profit-seeking channels provided by copyright. ${ }^{14}$ As a case example, one of

${ }^{10}$ The infinite variety of creative products, including music, could be described for example in case of two different music, they are not identical, but they can and do differ in two ways that themselves have diverse consequences. They could have similar character or quality, but they are not identical (Richard E. Caves, supra note 2, at 6). As an example, Queen and Led Zeppelin could have similar genre or mood of music, but they are different and can be differentiated to each other, in which each has its own character and interpretation of music. Some consumers could prefer Queen over Led Zeppelin, others could choose otherwise. Some of them may also like and enjoy music from both bands, and in such case the bands may have different entertaining value for the consumers.

${ }^{11}$ As a creative product, music is an 'experience good,' in which the consumers' satisfaction will be a subjective reaction. The producer's intimate knowledge of the good's production process still leaves him in the dark about whether consumers will like it (Ibid., 3).

${ }^{12}$ As aforementioned, in the sociographs the actors are represented as 'points.' Such points may be directly connected by a 'line,' or they may be indirectly connected through a sequence of lines. A sequence of lines in a graph is a 'walk.' and a walk in which each point and each line is distinct is called a 'path.' (See John Scott, supra note 8 , at 68 ).

${ }^{13}$ William Patry mentions an idea of 'artificial scarcity', in which the actors, namely record labels and distributors, act as 'gatekeepers' controlling the access and availability of music by limiting the channels and paths to music products, making it scarce enough to higher its value in the market, thereby inducing more profits for the business. However, in this new music economy, where communication technology has lowered the barrier for music flows, everyone connected to the Internet and cloud-based networks could access and acquire music, making it less scarce, and its market value then goes down. (See William Patry, supra note 10).

${ }^{14}$ As UK's PRS for Music Chief Executive, Robert Ashcroft, stated that the Internet has allowed the free flow of information and entertainment content, and increased demand for music has been accompanied by a distortion in its market value. He mentioned that in PRS for Music's annual Adding up the UK Music Industry 
the file-sharing sites called Limewire has to face the lawsuit filed by record labels and publishers, since the music available through Limewire has been considered unauthorized. ${ }^{15}$ In such situation, the enforcement of exclusive copyrights indeed facilitates the exclusion of competitors because the distribution of music is restricted only to those actors who have the authorization for such distributing activities. The social network approach which is adopted in the present paper helps illustrate that the competition as affected by the technology and cloud computing is apparently not between the actors, but more on the channels to distribute and access the music within such networks.

As regards the networks and the distribution and dissemination activities, there are three key notions of diversity, innovation, and quality, which account for analysis in this paper. The term 'diversity' shall refer to the outcomes of music distributed and disseminated; the 'innovation' of communication and networking technology as the tool to achieve such diverse outcomes; and the 'quality' as the standard in assessing: (1) the respective music distribution networks; (2) the innovation they possess; (3) and the diverse music outcomes that they can support and facilitate to reach the consumers.

\section{Overview of the Conventional Music Distribution System}

This section will outline the reality of distribution and dissemination of music. Here, the two models of music business - the conventional model and distribution model by means of Internet and cloud computing technologies - are described. In order to crystallise the modalities of these two different ways of music distribution, we adopt a networking approach which requires to identify relevant channels or paths for music distribution and access, the necessary connections or interactions, flows of music from one actor to another, as well as the 'distance' ${ }^{16}$ which indicates the number of intermediaries (i.e., degree of separation) ${ }^{17}$ that certain actor needs to get through to in order to access or distribute the music.

report, published on August 2011, it was found that both piracy and competition from other forms of entertainment continue to diminish music revenues, in which recorded music income fell by nearly eight percent on 2010, as consumers spent less on CDs and DVDs. (Robert Ashcroft, The Big Issues, posted on September 26th, 2011, via m-magazine.co.uk, accessed on March 8th, 2012, m-magazine.co.uk). See also: Leigh Beadon, RIAA's Cary Sherman: We Really Just Want To Give Consumers What We, Er, They Want, posted on Monday Mar 5th, 2012, available at techdirt.com/articles/20120304/22195417974/riaas-cary-sherman-we-really-justwant-to-give-consumers-what-we-er-they-want.shtml?utm source=dlvr.it\&utm medium=twitter. It was also reported in 2009 that the global recorded music trade revenues was US \$17 billion, a decline of $7.2 \%$ from 2008 , and physical sales continue to fall by $-12.7 \%$, which is a slowing decline from $-15 \%$ the year before. (Helen Gammons, supra note 2, at xix.)

${ }^{15}$ Joe Mullin, Limewire Settles with Music Publishers But Keeps Fighting Record Labels, posted on March 9, 2011, accessed from: paidcontent.org/2011/03/09/419-limewire-settles-with-music-publishers-but-keepsfighting-record-labels.

${ }^{16}$ The 'distance' between two points (or, actors) is the length of the shortest path that connects them. (John Scott, supra note 8, at 68; and Christina Prell, supra note 8). A shorter 'distance' would likely to assure better quality of communication (A. Bavelas, Communication Patterns in Task-Oriented Groups, The Journal of the Acoustical Society of America 1950, 22-6: 725-730; and S. P. Borgatti, Centrality and Network Flow, Social Networks 2005, 27: 55-71).

${ }^{17}$ See Albert-Laszlo Barabasi, Linked (Cambridge: Perseus Publishings, 2002); D. J. Watts and S. H. Strogatz, Collective Dynamics of "Small-World" Network, Nature 4 June 1998, Vol. 393: 440-442; D. J. Watts, Small Worlds - The Dynamics of Networks Between Order and Randomness (Princeton: Princeton University Press, 1999); and D. J. Watts, Six Degrees - The Science of a Connected Age, W. W. Norton \& Co., 2003. 


\subsection{Conventional Model of Music Distribution}

The chain of distribution and dissemination of music can be represented by a network consisting of three groups of actors, namely: (1) artists, (2) professional intermediaries, and (3) information receivers (or, consumers). In this stage of conventional music distribution, the professional intermediaries play an essential role and perform various functions in delivering music to the market ${ }^{18}$ :

a. Record labels, who make investment and facilitate the recording of music, including further reproduction and promotion of the recorded music, and supply them to the music distributors, music stores, broadcasting organizations, etc., so that the music products can reach the consumers;

b. Music distributors, suppliers, and retailers (physical music products), who provide copies of music in physical form, i.e., vinyls, CD's, and cassettes, and procure them through the music stores;

c. Broadcasting organizations, which encompass TV and Radio, who broadcast and airplay the music and live shows to the consumers;

d. Touring and live concerts/performance promoters or agents, including entertainment places such as pubs, clubs, hotels, shops, concert halls, etc.; and

e. Other actors engaged in music distribution and publication, such as audio and video jukebox suppliers, sheet music retailers, telecommunication companies providing ring tones or ring back tones service, karaoke, and synchronization activities of using the music for motion pictures, advertisements, and games.

In this conventional music distribution model, such actors interact with each other; their operation is generally based upon authorizations and exclusivity framed under copyright. Those actors play their own roles and functions in the network of music distribution activities. Actually, respective paths for music distribution network involve various intermediary actors. This means that for each deal there are various transaction costs associated with the construction of the connection or path. In addition, at every layer of music distribution through such intermediary actors, a selection activity also applies. For instance, during the process of music recording, the record labels conduct certain selection methods in choosing the artists they want to deal with. ${ }^{19}$ As a result, only a relatively small percentage of artists and music created could reach the market. ${ }^{20}$ An illustrated graph of the networking of conventional music distribution is given below.

\footnotetext{
${ }^{18}$ The essential role of the professional intermediaries can be considered as a kind of filling the structural holes, which is the basis of their power to control the network. The structural hole refers to the separation between contacts that are disconnected in some way, either directly, in the sense that they have no direct contact with one another, or indirectly, in the sense that one has contacts that exclude the others. (See R. S. Burt, Structural Holes: The Social Structure of Competition (Cambridge: Harvard University Press, 1988), 18). In this sense, the professional intermediaries connect the separated contacts, and could have the power on such connecting function by excluding others.

${ }^{19}$ As regards to broadcasting organizations, they mostly will choose to airplay the music that has potential to be a 'hit' provided that such music comes from credential record labels that have also conducted initial selection of the music to be recorded. The practice of payola (paid radio airplay) had even sharpened such selection of playlists, when the music being able to be airplayed (especially in prime time) is only the one that is supported by fine funding for the payment of such payola. This also as regards to their roles as 'gatekeepers' to the music market. The infinite variety of music created, adding the fact that nobody knows whether certain music will be successful in the market, induce the professional intermediaries having roles to bring the music to the market to selection which music (and which artists) that has greater potentiality to be successful in the market. (See Richard E. Caves, supra note 2).

${ }^{20}$ Patrik Wikstrom, supra note 3, at 55-6 and 66.
} 


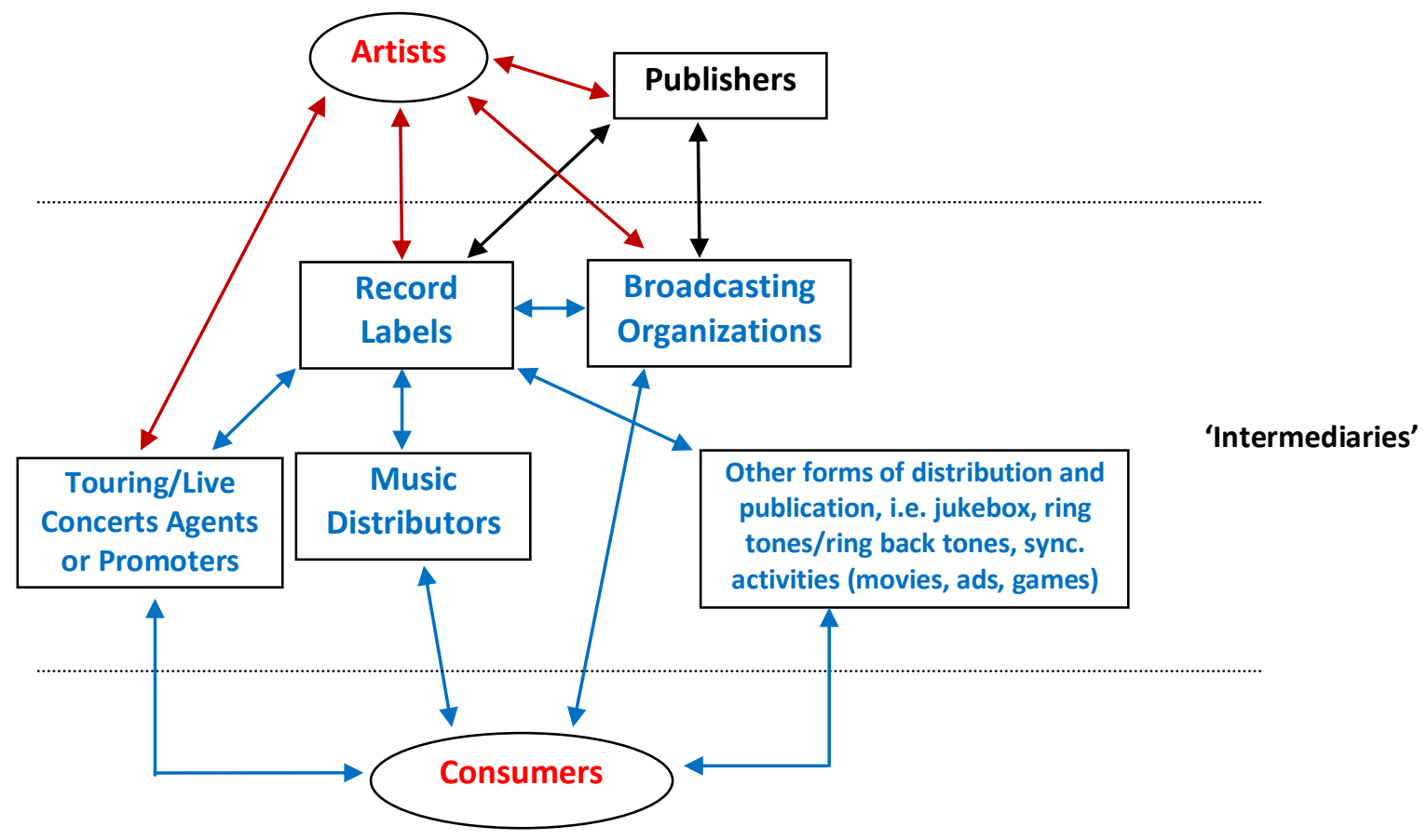

Figure 1: Complex networking graph of conventional music distribution system

The network of music distribution through such intermediaries substantially starts from record labels or publishers, who then construct other channels or connections to other intermediary actors in bringing music to the market. Exclusivity and authorizations possessed on the basis of copyright by the intermediaries helps them exclude competitors from distributing the music. Further, this also enables the intermediaries to restrict paths through which consumers can access music (e.g., records supplied to music stores only by authorized music distributors, or limited broadcasts through the TV and Radio, in which not all music delivered by record labels will get the same treatment of promotion and airplays). As a result of this system some music products get highly exposed, while others not.

In this model, there is longer 'distance' for consumers to connect with the artists and other actors because they have to pass through multiple layers of intermediaries (e.g., record labels, music distributors, and broadcasting organizations). Besides, there is limited 'channel capacity $^{21}$ for artists to distribute their music and for consumers to access the music. Such layers of intermediary actors conducting the selection of distributed music, as well as limited and exclusive channels of distribution, may affect the diversity of distributed music. Less competition will eventually reduce the diversity of the distributed music because the outcomes will depend on the monopoly and control of the intermediary actors who have exclusive copyright and therefore could (arbitrarily) determine what music should be distributed and disseminated to the consumers.

The simplified Figure 2 below illustrates the distance between the artists and consumers in the activities of music distribution and access. It is shown that the distance from consumers to

${ }^{21}$ The 'channel capacity' refers to the available channels for music access, which could be from different existing paths, such as from music stores, from TV or Radio, etc. 
the artist is 3 (three) - three lines involving two intermediaries (record labels and distributors or broadcasting organizations).

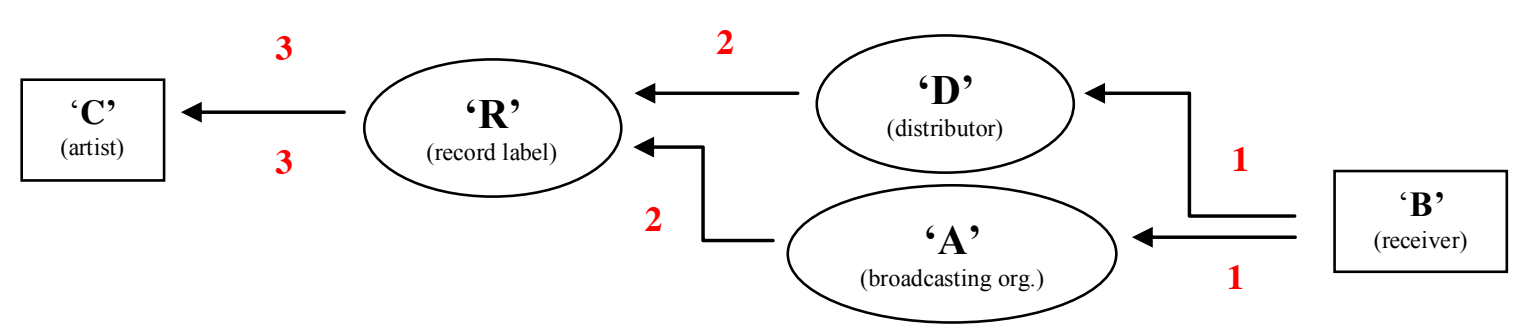

Figure 2: An example graph of conventional music flow, distance between $B$ and $C$ is 'three'

\subsection{Limited Diversity of Distributed Music under Conventional Model}

The exclusive paths and limited channel capacity provided by the intermediary actors in conventional model indicate a condition of 'oligopolistic' market, where distribution of certain music is controlled by those certain numbers of intermediary actors. This as also relevant to the exclusivity and authorizations they obtained on the basis of the copyright framework. Although we are not aspiring to explain every possible case, the following simulation is aimed to provide an empirical observation concerning such oligopolistic market where the diversity of distributed music to the consumers may be much lower.

The actors that have strong position as intermediaries in music distribution networks could determine what music to be distributed and broadcasted. The music not employed by intermediaries having strong position is likely to become less and less exposed. Inside the network connecting the artists and consumers, such intermediaries - both the strong as well as less strong ones - play the role of 'gatekeepers,' who decide which music is to be distributed and which music is not. These intermediaries are able to control the flow of music distribution and affect the outcomes (i.e. what music is disseminated). ${ }^{22}$ Illustrated simulations are provided below.

${ }^{22}$ Ronald S. Burt described this condition as 'structural holes' where the distance between two actors is 2 (two) and not 1 (one), allowing third actor to act as an intermediary.(See R. S. Burt, supra note 21). 

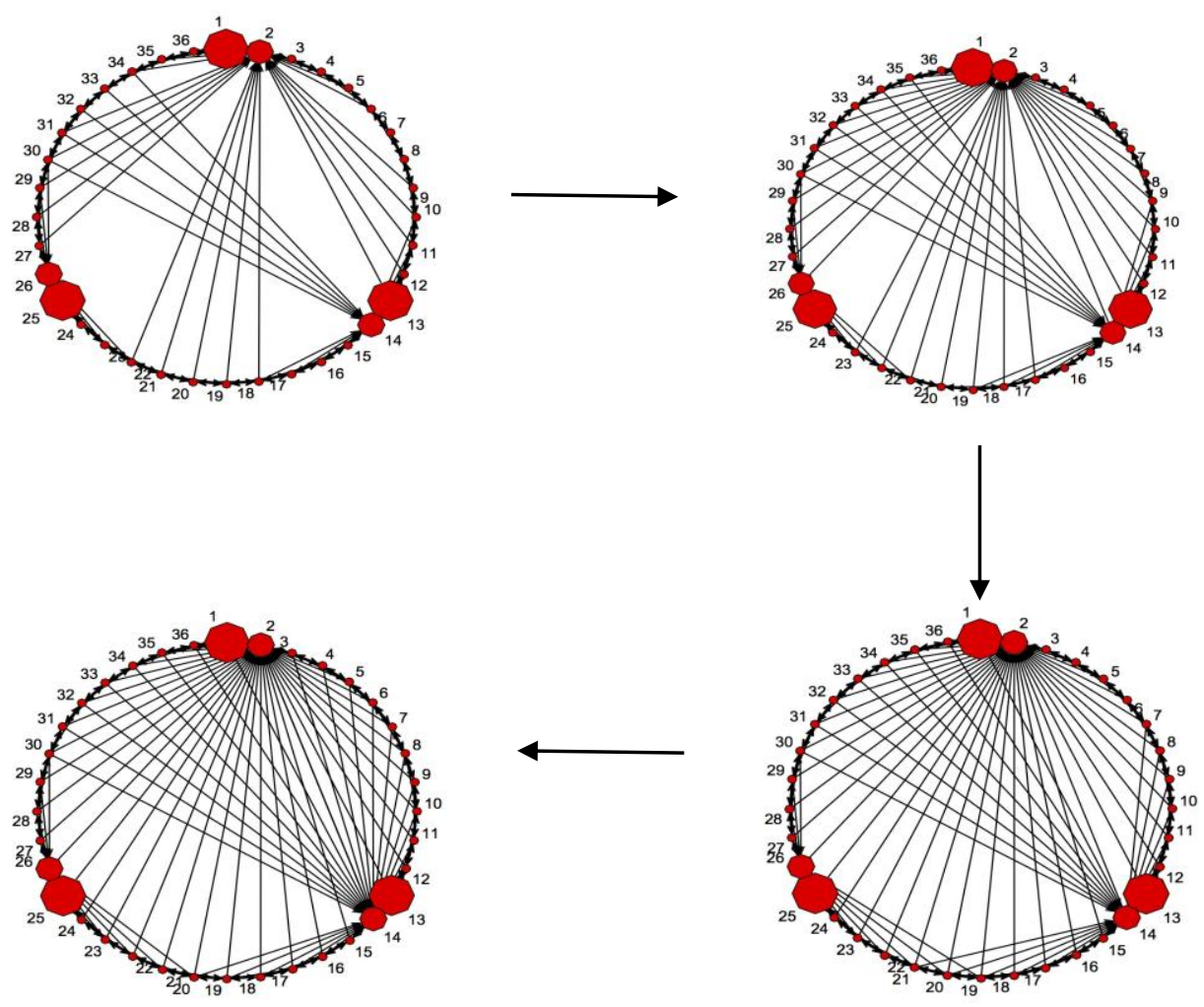

(The circle graph) 

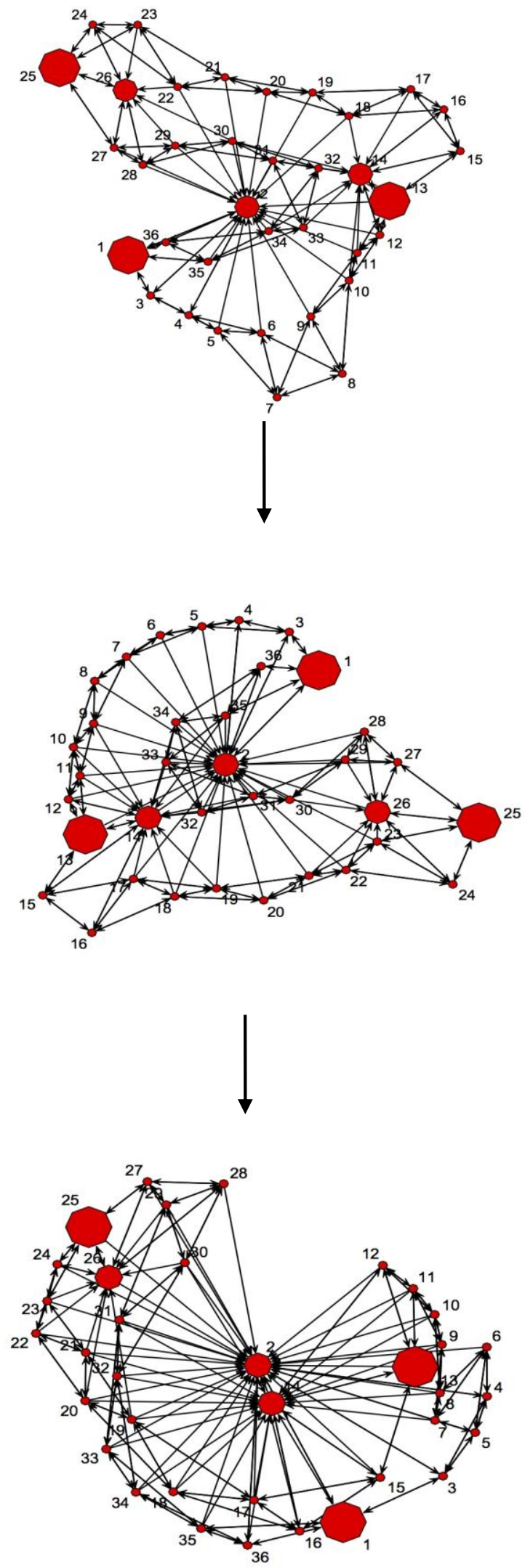


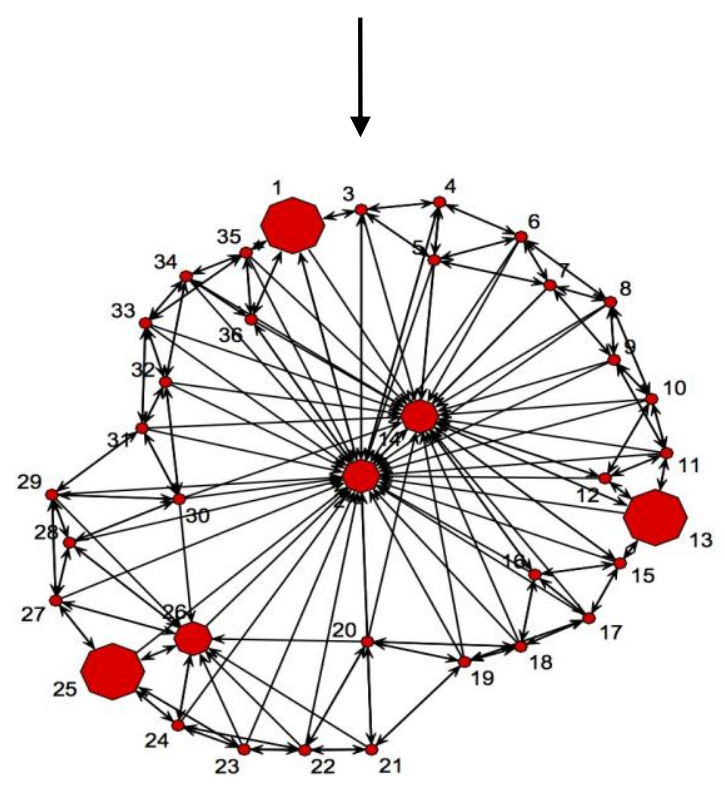

(The graph in gravity mode)

Figure 3: Changing network status with two strong intermediary actors and one weak intermediary actor

The assumptions or models to conduct the simulation generating the above graphs are described in the table below:

\begin{tabular}{|c|l|}
\hline \multicolumn{2}{|c|}{ Assumptions } \\
\hline 1 & $\begin{array}{l}\text { There are } 36 \text { actors in the network. } \\
\text { They are called as actor }{ }_{1}, \text { actor }_{2}, \text { actor }_{3}, \ldots . \text { actor }_{36},\end{array}$ \\
\hline 2 & Actor $_{1 \text { to } 36}$ are located on a circle in numerical order. \\
\hline 3 & $\begin{array}{l}\text { Every actor has both directed ties with its four nearest neighbors. } \\
\text { Accordingly, the information originated or received by one actor will } \\
\text { be transmitted to its four nearest neighbors. Also, any actor will } \\
\text { access the information originated or received by any of its four nearest } \\
\text { neighbors. } \\
\text { This is to represent the communication with neighbors in vicinity. }\end{array}$ \\
\hline 4 & $\begin{array}{l}\text { Actor }{ }_{1,13,25} \text { are the originators of information. They will originate new } \\
\text { information. Any other actors will not originate any new information, } \\
\text { and they will just receive directly or indirectly information originated } \\
\text { by actors }{ }_{1,13} \text { or } 25 \text {; and re-transmit it to other actors. }\end{array}$ \\
\hline 5 & $\begin{array}{l}\text { Actor }{ }_{2,14,26} \text { are the commercial intermediaries of information. Each of } \\
\text { them will receive new information created by an originator in its } \\
\text { adjacency and will try to transmit it to multiple actors beyond its } \\
\text { neighborhood or vicinity. }\end{array}$ \\
\hline 6 & $\begin{array}{l}\text { Actor }{ }_{2} \text { sends an 'arc' to actor }{ }_{1} \text { (i.e., there is an incoming tie reaching } \\
\text { actor } \text { from actor }_{2} \text { ). This is to represent that individual commercial } \\
\text { distributor distributes information from limited number of source. }\end{array}$ \\
\hline
\end{tabular}




\begin{tabular}{|c|c|}
\hline & $\begin{array}{l}\text { Then, actor }{ }_{2} \text { will try to disseminate the information newly created by } \\
\text { actor1 through the network. In this respect, actor } 2 \text { is the commercial } \\
\text { intermediary with strongest power to disseminate information. At the } \\
\text { default stage, it receives arcs not only from its four nearest neighbors } \\
\left(\text { actor }_{36,1,3,4} \text { ), but also from actor } 5,10,11,12,19,20,21,28,29,30,35 \text {. }\right.\end{array}$ \\
\hline 7 & $\begin{array}{l}\text { Actor }{ }_{26} \text { sends an arc to actor }{ }_{25 .} \text {. Then, } \text { actor }_{26} \text { will try to disseminate the } \\
\text { information newly created by actor }{ }_{25} \text { through the network. Actor }_{26} \text { is } \\
\text { the commercial intermediary with weakest power to disseminate } \\
\text { information. At the default stage it receives arcs only from actor } 23,24 \text {, } \\
25,27,28,29 \text {. }\end{array}$ \\
\hline 8 & $\begin{array}{l}\text { Actor } 14 \text { sends an arc to actor }{ }_{13} \text {. Then, actor }{ }_{14} \text { will try to disseminate } \\
\text { the information newly created by actor }{ }_{13} \text { through the network. Actor }{ }_{14} \\
\text { is the commercial intermediary with second strongest power to } \\
\text { disseminate information. At the default stage it receives arcs not only } \\
\text { from its four nearest neighbors (actor } 12,13,15,16 \text { ), but also from actor }{ }_{11} \text {, } \\
17,31,32,33 \text { ). }\end{array}$ \\
\hline 9 & $\begin{array}{l}\text { If any actor (other than commercial intermediaries) gains two or more } \\
\text { paths reaching a commercial intermediary with separation degree of } 2 \text {, } \\
\text { the former directly sends an arc to the later. } \\
\text { This is to represent our tendency to buy an entertainment content } \\
\text { directly from a commercial intermediary if our neighbors (friends, } \\
\text { colleagues, etc.) tell us about their attachment to the content. }\end{array}$ \\
\hline 10 & $\begin{array}{l}\text { If any actor (other than commercial intermediaries) gains arcs to three } \\
\text { commercial intermediaries, it will eliminate the arc to the commercial } \\
\text { intermediary, who receives least number of arcs from the actors who } \\
\text { have both directed ties with the said actors. If two or more } \\
\text { commercial intermediaries are in the same rank, no arcs sent to them } \\
\text { are dissolved. } \\
\text { This is to represent our tendency to buy contents from commercial } \\
\text { distributors who are popular in our neighbors. }\end{array}$ \\
\hline 11 & $\begin{array}{l}\text { Once disconnected, an arc sent from an actor to a commercial } \\
\text { intermediary will never be restored. } \\
\text { This is to represent our tendency that we rarely buy a content again } \\
\text { from a commercial distributor once we abandoned such access. }\end{array}$ \\
\hline 12 & $\begin{array}{l}\text { The exiting connecting and disconnecting arcs will be repeatedly } \\
\text { constructed, until any new arc can be connected or constructed. }\end{array}$ \\
\hline
\end{tabular}

The implication of the simulations could be described as following. First, the actors in the vicinity of the artists may access their music directly. However, the artists themselves may not be able to distribute and disseminate their music widely. Therefore, the role of intermediaries (in 'between') becomes essential in delivering music to the consumers. For example, actor ${ }_{13}$ (an artist) connects with actor ${ }_{14}$ (an intermediary) who is in a better position to induce incoming access from other actors. The same happens with actor ${ }_{1}$ (an artist) and 
actor $_{2}$ (an intermediary), as well as actor $_{25}$ (an artist) and actor 26 (an intermediary). The intermediary position of actor $2,14,26$ helps fill the gap and facilitates creating paths between consumers and the artists. Second, actor 2 and actor ${ }_{14}$ can have more incoming ties from many actors, both in vicinity and remote places, indicating their stronger positions in the network as compared with others. In contrast, actor ${ }_{26}$ has incoming ties mostly from the actors in vicinity, indicating less strong position than actor 2,14 . The stronger intermediaries gain more and more incoming ties, while the weaker intermediaries gain less incoming ties.

Based on the above simulation, the ties ${ }^{23}$ representing ability to disseminate for wider area help draw distinction between powerful intermediaries and weak intermediaries (who only have ties with actors in their vicinity, or, at best, very few remote actors). In reality, an example could be in the case of music distribution by major record labels and independent record labels. The actor 2 and actor $_{14}$ could be considered as the major record labels with strong position indicated by a vast number of incoming ties ${ }^{24}$, while the independent record label could be illustrated as actor 26 , with only several incoming ties from actors in its vicinity.

By converting the assumption of the simulation above, one more implication can be derived. Assume that actor ${ }_{1,13,25}$ are the consumers, while that actors other than actor ${ }_{1,2,13,14,25,26}$ are artists. Assume also that each artist connect and disconnect ties with professional intermediaries (actor ${ }_{2,14,26}$ ) so that they increase the probability that they are connected with respective consumers with distance " 2 ". The professional intermediaries in stronger position successfully establish incoming ties from more and more artists. Naturally, they become majors who are able to choose arbitrarily (on their respective considerations) what music to be delivered to the music distributors and broadcasting organizations, who depend on the majors in accessing the music. In practical terms, this means that the diversity of music outcomes is reduced, unless strong intermediary actors remain neutral.

Under both assumptions, the resulting graph shows an oligopolistic structure of music distribution market where several strong intermediaries have more incoming ties than the less strong ones. The music distributed by the less strong intermediaries can only reach consumers in their vicinity; therefore there is a risk of unrecognized (even vanishing) music in the network.

\section{Distribution and Dissemination of Music Affected by the Internet and Cloud Computing Technology}

In music flows between the actors, various paths of different distances can be identified. Both - paths and distances - depend upon the goals of such music flows. For instance, in a case of intermediating distribution and dissemination of music, there could be a path with short length ${ }^{25}$ (or direct path) from the artists to the intermediaries, i.e., record labels.

\footnotetext{
${ }^{23}$ The ties are established from constructed paths between the points (or, actors). Such paths, which consist of arcs (or, lines) could be a 'positive' or 'negative' relations (or connections), and could have 'directions' toward each other. The direction attached to an arc is a way of distinguishing, for example, actor A's orientation to B or B's orienttation to A. Thus, establishing an incoming or outcoming ties for such actor. (See John Scott, supra note 7 at 11 and 13; and Christina Prell, supra note 8, at 9).

${ }^{24}$ An actor could be said as having incoming ties, when a constructed path (or, number of arcs) are directed to it from number of other actors. (Ibid.).

${ }^{25}$ The 'length' of a path is measured by the number of lines (arcs) that make it up. (See John Scott, supra note 8 , at 68 ).
} 
However, there could be also longer paths in cases when artists connect with broadcasting organizations through the record labels, or when artists try to reach the consumers intermediated by record labels and broadcasting organizations. This means that the flows of distribution and dissemination of music involve two kinds of connections: (a) short length paths and (b) paths from any-to-any.

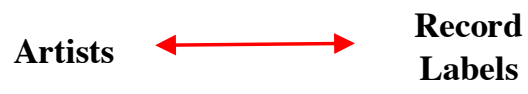

Figure 5. Short length path: a direct path from record labels to access and obtain artists' music.

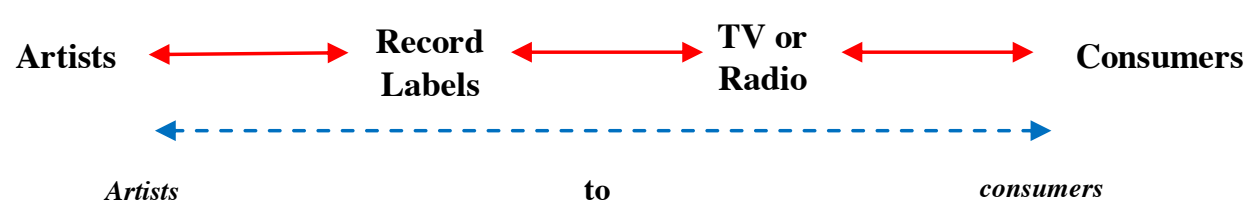

Figure 6. Any-to-any. A path with longer distance from consumers to access and obtain artists' music

\subsection{Music Distribution: Short Distance and Any-to-Any}

The Internet and cloud computing technology have enabled the shortening of distances between the artists and consumers. In an earlier case of the conventional music distribution and dissemination model, the existence of paths for distribution was predetermined by the existence of record labels, music distributors and broadcasting organizations. However, the emergence of innovative online music sites provides for shorter paths for consumers to access the music created by the artists. Such digital technologies made it possible to acquire music without visiting music stores, purchasing physical copies or watching/listening the music broadcasts through TV/Radio at a specific time. For instance, an online music site named Bandcamp ${ }^{26}$ provides a platform for artists to share their music to be accessed by consumers who visit the site. The site also enables consumers to purchase online or download the music from artists they found in Bandcamp. Most of the artists are independent and have recorded their music under independent record label, or without any label, and do not engage in any official record or distribution deals, except with the respective intermediary - Bandcamp who delivers their music through the Internet to the consumers.

In this respect, the occurrence of such innovative intermediary sites had an impact on the dependency relations between the artists, record labels, distributors, and broadcasting organizations. The flows of music through such sites could reduce the distance that exists between the artists and consumers in the case of the conventional music business model. In other words, the any-to-any channel, i.e., from artists to consumers, which in the conventional model requires long path with several intermediaries, could be shorten with facilitation by the innovative Internet intermediary. In this regard it should be mentioned that the digital technology and the Internet have enabled 'shortcuts' as by-passing several intermediaries, with one essential innovative intermediary through which the consumers can access music from their favourite artists (as in the case of Bandcamp). The artists could

\footnotetext{
${ }^{26}$ The site can be accessed at this link: http://bandcamp.com/.
} 
choose to go independently ${ }^{27}$ and distribute their music through the Internet intermediaries, aside from having conventional paths of engaging with record labels or physical-based music distributors.

Moreover, the Internet and cloud computing have also facilitated access and enjoyment of music in any desirable way at the consumers' choice. There is a time-shifting ${ }^{28}$ phenomenon which means that consumers can nowadays access and enjoy music anywhere and at any time they prefer because the Internet and cloud computing services provide online music sites. For example, the innovative online music subscription sites such as Spotify or Last.fm ${ }^{29}$ provide features of music services, i.e., music streaming, that the consumers can choose to enjoy music they like. There is also Drip. $\mathrm{fm}^{30}$ from which consumers can subscribe for music directly from the record labels. Such example shows that not only the artists could make use of the Internet and cloud computing to shorten the length of the path for music distribution and access, but also the record labels, and in many cases, also the music distributors, such as through iTunes, and broadcasting organization through its official sites, such as BBC Radio.

The emergence of these neutral innovative online music intermediaries have also opened more opportunities for artists to distribute and disseminate their music without having to pass the selection stages of conventional model. This means that any kind of artists having sufficient skills in utilizing technology, including the audio-recording ones, can start their own music recording process independently from any official record label, create the master of the music, and make it available through the innovative Internet intermediary sites ${ }^{31}$. The communication network and technology through the Internet and cloud computing have enabled even music from some remote areas to be accessed and disseminated worldwide. This also leads to a more diverse music disseminated in the music market because the role of such conventional gatekeepers (i.e., record label, distributor, and broadcasting organization)

\footnotetext{
${ }^{27}$ Studies have been conducted in examining whether the emerging technology and innovation in music business have made it possible for the musicians to build their career independently, or the so called 'do it yourself' activities, in which recent innovative intermediary sites could bring impacts to those independent musicians' career and music flow's paths. Of all the suggestions to effectively manage the career independently is to choose the persons and expertises carefully to support the musicians' career (See Donald S. Passman, supra note 2 , at 12). In the paths, the musicians do not have to engage with institutional actors such as record labels, but they can cooperate with personals as team members, considering the team could strategically and effectively support the musicians' business and music projects. One of the sudies is available at: money.futureofmusic.org/teams.

${ }^{28}$ The time-shifting concept was mentioned in the case of Sony Corporation of America v. Universal City Studios, Inc. 464 U.S. 417 (1984) in which a videotape recorder ("VTR"), called as Betamax, manufactured by Sony, enables consumers to videotape copyrighted television product off the air for later private viewing, shifting the time for access of the TV program. See Robert Burrell and Alison Coleman, Copyright Exceptions: The Digital Impact (Cambridge: Cambridge University Press, 2005, at 258-59). In the case of music, the current technology including those of gadgets for music players and easy access through the Internet and cloud have facilitated the time-shifting in enjoying music into anytime and anywhere, and not necessarily through certain scheduled broadcasts or live shows which services are limited only within such time.

${ }^{29}$ The sites can be accessed at this links: Spotify - spotify.com/int/, and Last.fm - last.fm/.

30 Available at: drip. $\mathrm{fm} /$.

31 The development of audio-recording technology has faciliated home recording process, in which the role of record label becomes diminishing. Such audio recording-technology has made it possible to sample, loop, and process sounds into completely new songs, arrangements and musical genres, and it has been said there has been gradual shift of the setting of creative works from the studio to the control room - a metaphor to describe the significant use of digital audio-recording technology. Digital audio-recording technology has made it possible to create the 'perfect' sound, with perfect pitch, perfect tempo, as well as perfect timbre, even though the artistic raw material might not be very musically gifted (Patrik Wikstrom, supra note 3, at 120).
} 
in controlling the outcomes of which music to be delivered to the consumers, are considerably diminishing.

Without having to engage with the gatekeepers, which means lower transaction costs with shorter length of paths, artists can distribute and disseminate their music to anywhere in the world. The use of the Internet is more cost-efficient if compared to the distribution of physical-copies. The distribution channels through such innovative sites basically resulted in the situation where any kind of music became available to the consumers. On the other hand, the consumers now also have alternative platforms from which they can search for any kind of music from any kind of artists. The channels for them to access music no longer limited to those oligopolized paths of record label, distributors, and broadcasting organizations. In this way, the innovative Internet intermediary sites have supported a more diverse music disseminated worldwide at a remarkably shorter distance and lower costs.

\subsection{Modelling the Remarkable Reduce of Distance}

It is empirically known that receivers of information have the tendency to reduce the degree that separates them from the source of information, to the extent that they consider such reduction is practical. Such tendency occurs because multiple degrees of connection (or, multiple layers of intermediaries) may degenerate the quality of information. Moreover, multiple layers of intermediaries could increase transaction costs ${ }^{32}$ of creation, maintenance, and enforcement of the relations and connections between them. Based on these considerations, it is assumed that any consumer has tendency to connect directly with a professional intermediary, when it has a path to reach the intermediary to reduce the distance to the artist. An example graph is provided below.

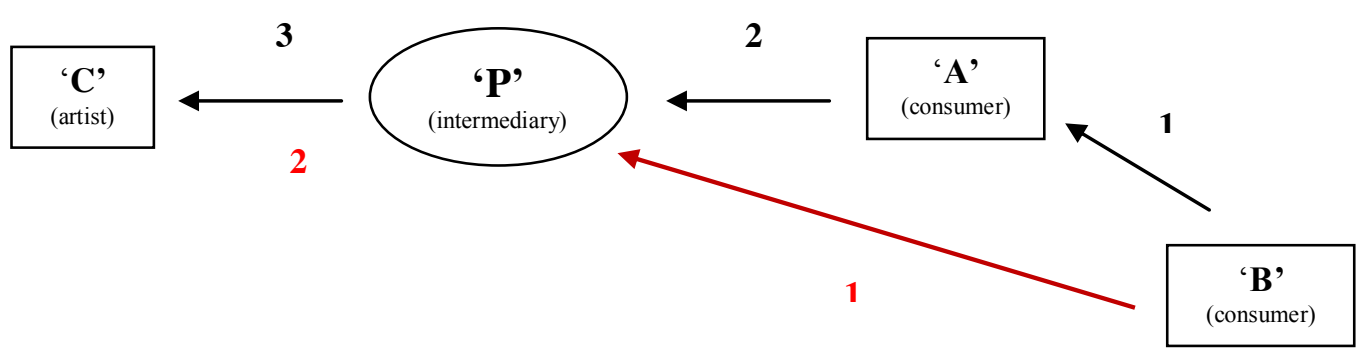

Figure 7. Dependency paths from consumers to access and obtain artists' music, reducing the distance

For instance, receiver ' $\mathrm{B}$ ' heard about the music of artist ' $\mathrm{C}$ ' from consumer ' $\mathrm{A}$ ', then $\mathrm{B}$ decided to establish a 'path' to intermediary ' $\mathrm{P}$ ' from which $\mathrm{B}$ can access and enjoy $\mathrm{C}$ 's music in shorter distance from $\mathrm{C}$. It is argued that the shorter the distance, the higher the quality of information received, because the information about the music received from word of mouth (received from A) has different degree of quality ${ }^{33}$ with the music provided by the official source, i.e. through professional intermediary. From such professional intermediary B

${ }^{32}$ The Coase Theorem describes transaction costs as generally include the costs of identifying the parties with whom one has to bargain, the costs of getting together with them, the costs of the bargaining process itself, and the costs of enforcing any bargain reached. (See Mitchell A. Polinsky, An Introduction to Law and Economics (New York: Wolters Kluwer Law and Business, 2011), at 14).

${ }^{33}$ In this context, the information delivered in longer distance or through word of mouth has risks of information errors, or influenced by subjective value of the transmitter of information. 
can actually experience and value the official C's music. In the graph, it could be seen that established connection from $\mathrm{B}$ to $\mathrm{P}$, has reduced the distance between $\mathrm{B}$ and $\mathrm{C}$ from 3 (three) to 2 (two).

With regard to the conventional distribution of music, for instance, if $\mathrm{B}$ (consumer) decides to establish direct connection with $\mathrm{P}$ (who is a music distributor or a broadcasting organization, such reduced distance will not have any substantial effect to the long flow of music, because there are still layers of intermediaries involved between the artists and consumers. Their involvement as gatekeepers will not essentially change the diversity of music disseminated, because the channels for music access mainly depend on such music distributor and broadcasting organization who have strong position and power to conduct the selection system for music distributed, thereby may not support the diversity of the music outcomes.

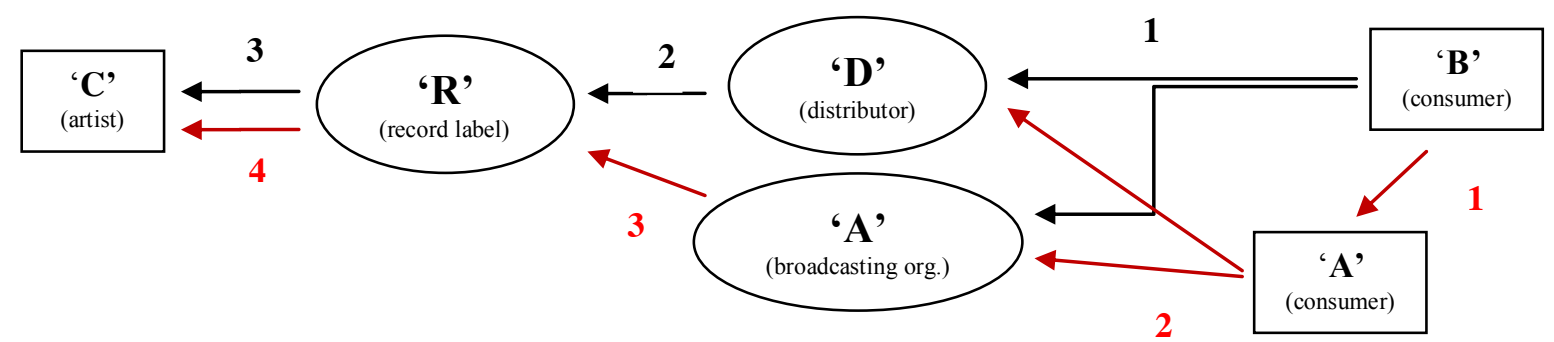

Figure 8. Conventional dependency paths to access music, reduced distance (from 'four' to 'three') between $B$ and $C$. The black lines indicate the path where $B$ establishes direct connection with the intermediaries (i.e., distributor and/or broadcasting organization)

As mentioned earlier, the innovative actors such as Internet intermediaries have significantly shortened the distance between artists and consumers. Figure 8 shows that the innovative online music sites have acted as the bridge 'between' the artists and consumers, by-passing the conventional paths of music distribution and dissemination through record label, distributors, as well as broadcasting organizations.

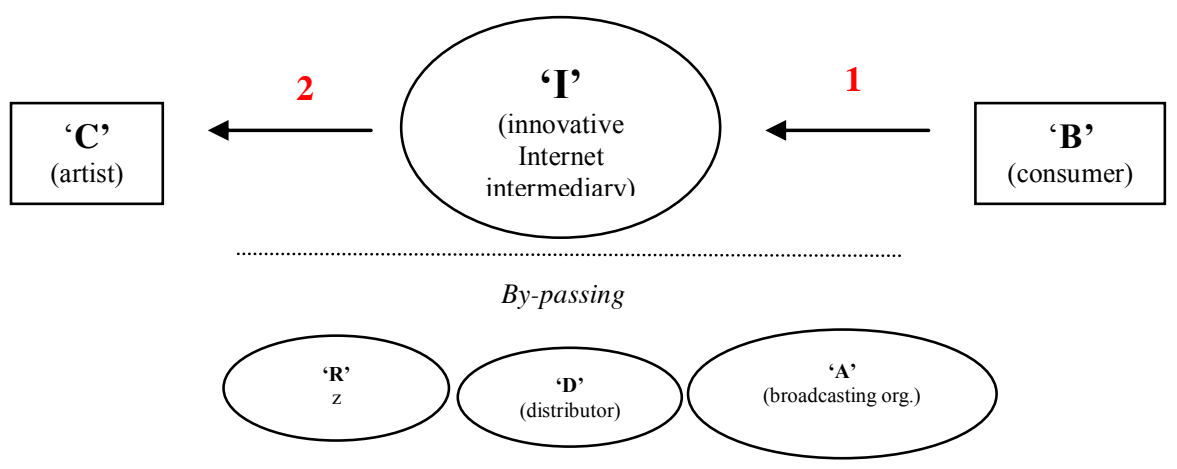

Figure 9. Shortcutted paths (distance between B and C is reduced into 'two')

These innovative sites have provided platforms that shorten the distance and replace longer paths of conventional model. Another example could the as following: a site called Reverbnation $^{34}$ provides platform to gather artists and consumers. By creating an account on

\footnotetext{
${ }^{34}$ The site is available at this link: http://www.reverbnation.com/.
} 
the site, various independent artists can share their music, and consumers can search for any kind of music that meets their tastes, outside the mainstream music in the market. The site has by-passed the music distributor and broadcasting organization in reaching the consumers.

In this respect, such remarkable reduction of distance has substantial effect in any-to-any channel of music distribution and access, such as from consumers to artists, and otherwise. This could improve the quality of music distributed, since it will not go through layers of intermediaries. The artists can also benefit from distributing and disseminating their music widely at lower transaction costs, since they can engage only with one sufficient Internet intermediary to disseminate the music using the networks of Internet. High cost of paths with layers of intermediaries may only work in an oligopolistic market, where exclusive paths and authorized production and distribution of music by the record labels, music distributors, and broadcasting organizations are possible to secure the economic 'rent'.

Thanks to intermediary sites in the Internet and cloud computing, not only the distance between the actors was reduced, but also the transaction costs have dropped significantly. In such circumstances, artists can make use of the sites and networking of Internet and cloud to widely disseminate their music without having to engage in the oligopolistic system of conventional music distribution model. The artists and consumers can maintain their alternative paths of music distribution and access through the innovative Internet intermediary sites, since it facilitates creation of shorter distances and minimized costs, as compared with the conventional ones. In the same vein, since the Internet and cloud computing opened the possibility for independent artists and intermediaries to participate and establish networks for music distribution, this change also could potentially promote more diverse music outcomes in the world market.

\section{The Star and Cloud Networks}

Following the discussion concerning the networking and flows of music distribution and access, the social network analysis recognises different types of networks, encompassing: (1) the 'star' network; (2) the complete graph; and (3) the 'cloud' network. Such networks could provide for different simulations on the paths of music distribution and access.

\subsection{The Star Network}

The networks for music distribution and access in the conventional model could be described as a 'star' network. In the 'star' network several intermediaries become the strongest and others less strong. As earlier illustrated in section 2.2, in a situation of a 'star' network, the stronger intermediaries will be and situated in the centre of the network, while the less strong intermediaries will be positioned in the fringe of such 'star' network. In this respect, the roles of music distributors and broadcasting organizations as gatekeepers from which almost all music outcomes are distributed and disseminated through them, represent a 'star' where they receive many incoming ties from any consumer ${ }^{35}$.

\footnotetext{
${ }^{35}$ A point (or in this context, the intermediary actor) is central, if it has a high degree of connection, meaning that it is connected to many other points, also in the sense that it is being 'well connected' or 'in the thick of things.' Such degree-based measure of point centrality, therefore, corresponds to the intuitive notion of how well connected a point is within its local environment. (John Scott, supra note 8, at 83, and Christina Prell, supra note 8, at 96-97).
} 


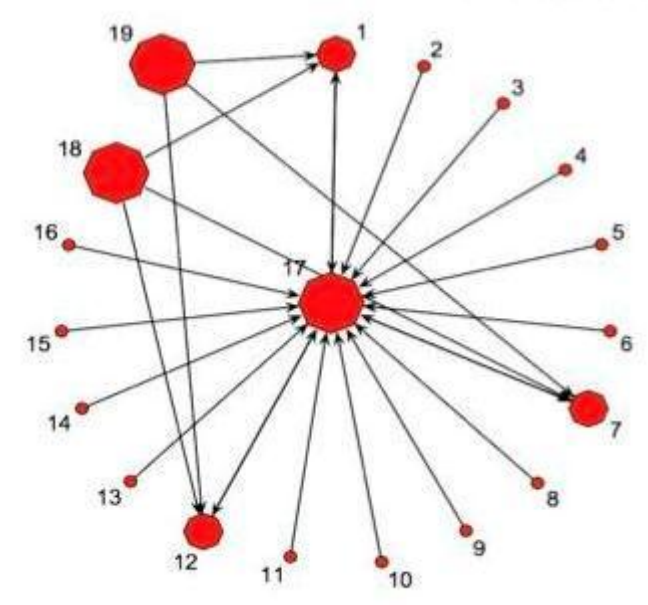

Figure 10. An example of a 'star' network

As mentioned earlier, the flows of music distribution and access in the conventional model require long path (and long distance between artists and consumers) involving layers of intermediaries. The artists and consumers themselves may not be able to afford all the transaction costs necessary to maintain and construct such paths. Therefore, the artists and consumers will depend on the intermediaries as gatekeepers to distribute and access the music, and this could benefit the intermediaries as they seek for economic rents and profits. Such condition only applies in a 'star' network, where exclusivity, authorizations, and oligopolistic music market can happen. The intermediaries having the power and position to widely distribute and disseminate music have a function as the 'hub' ${ }^{36}$ actor (or, 'hub' of the 'star' network).

However, as the consequence for enduring the cost and maintaining the long path of distributing and disseminating music to the market, such intermediaries will base their decisions on choosing the music that has the commercial quality, so that it could bring the desirable profits. With strong position in the networks, the commercial intermediaries can have power in the music market, while smaller intermediaries (perhaps with much diverse and less commercial music motives) rarely reach wide audience of consumers. This leaves consumers with options of easy music access from commercial intermediaries' channels, from which the music outcomes may be rich, as coming from many popular artists, but considerably less diverse, since they come from the mainstream (yet, commercial) music. A conventional oligopolistic music industry represents this circumstance.

\subsection{The Complete Graph}

In contrast with the star network, in a complete graph network every actor can reach every other actor with only one degree of separation ${ }^{37}$. This, arguably, can be achieved with the emergence of shortcuts facilitated by the Internet and cloud computing. Thus, the average distance between the actors, including between the artists and consumers, as well as between

${ }^{36}$ The centrality in a network could be illustrated by sociograms in which a central point is the 'hub' of a series of radiating 'spokes' which connect it to the more peripheral (surrounding) points. (John Scott, supra note 8, at 143). The 'hub' may also fall between all the other points, and it has the shortest path lengths (or distance) to all other actors, making it the closest actor to all the others, thereby serves as a 'hub.' (See also Christina Prell, supra note 8, at 97).

37 John Scott, supra note 8, at 69-70. 
the consumers themselves is reduced. In such network, everybody can connect with each other with shortest distance possible, and yet, at a minimum cost. This can promote more diversity of music disseminated from artist to (and among) the consumers in the network. Illustrated simulations of network with shortcuts provided below ${ }^{38}$.

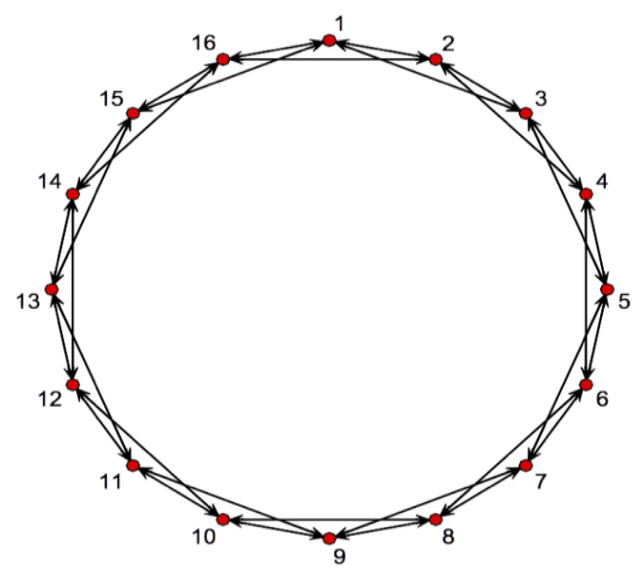

Figure 11. A network with no shortcut. Short distance could only be achieved between actors in vicinity, while to connect with remote actors, longer distance applies, i.e. from actor 4 to 8.

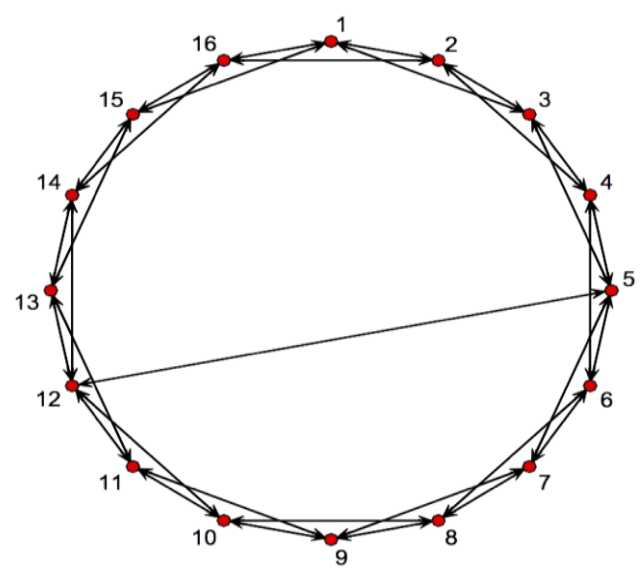

Figure 12. Example of a network with one shortcut. Reducing the average distance from actor 2 to reach actor 8 .

${ }^{38}$ D. J. Watts and S. H. Strogatz, Collective Dynamics of "Small-World" Network, Nature 4 June 1998, Vol. 393, 440-442; D. J. Watts, Small Worlds - The Dynamics of Networks Between Order and Randomness (Princeton: Princeton University Press, 1999). 


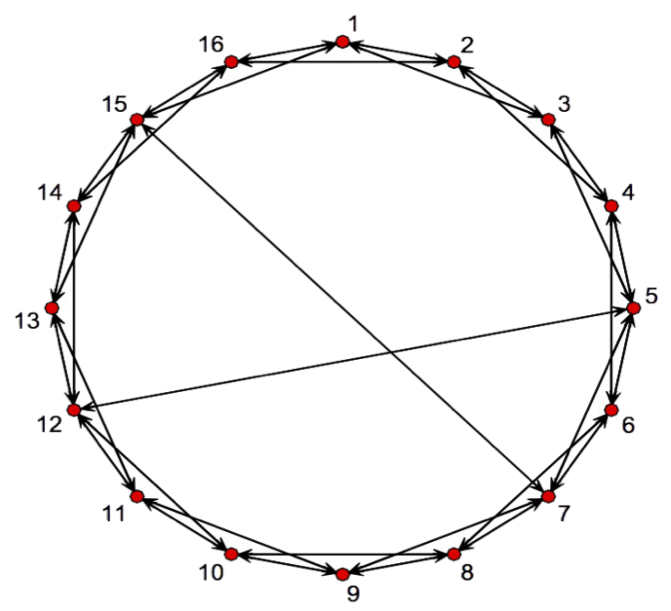

Figure 13. Network with two shortcuts. Reducing more average distance between the actors.

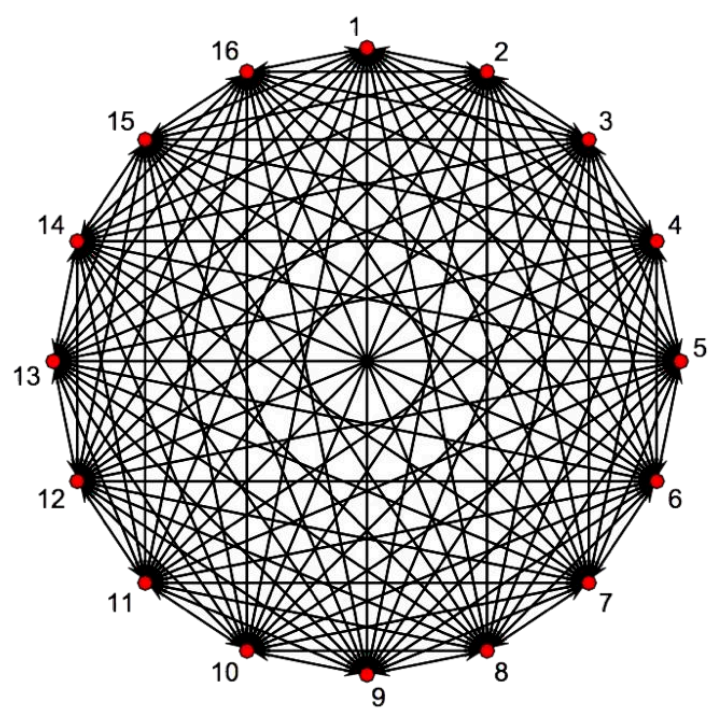

Figure 14. A complete graph network, in which all actors are connected in shortest average distance of ' 1 ' (one). 
However, such model of a complete graph may not be realistic, since in the real circumstances there are a lot of artists, intermediaries, as well as consumers involved ${ }^{39}$. Even though theoretically the simulation shows that in the complete graph network facilitated by the Internet and cloud, everybody can connect with everybody in distributing and accessing the music, in reality that may not always happen and considered effective for the distribution of music. For instance, a consumer who connects directly with the artist may not always redistribute such music to other consumers, and even if he or she did so, the other consumers may not always well-receive or give positive response to the information ${ }^{40}$.

\subsection{The Cloud Network}

If in the star network there are only limited channels and paths of music distribution and access, and the complete graph network will not always be realistic, the 'cloud' network is constructed through a combination of both the star and complete graph networks. In this respect, the cloud network departs from a star network with hub actor as the intermediary. However, such hub actor is a neutral ${ }^{41}$ one possessing the necessary criteria to shorten the distance with less cost, as well as can distribute and disseminate music widely and quickly, thereby can virtually actualize a complete graph ${ }^{42}$.

\footnotetext{
${ }^{39}$ According to Christina Prell, in a complete network, all actors in the network are known beforehand and where the ties linking these actors together could then be measured. However, the network of music distribution and dissemination as affected by the Internet and cloud computing technology have made it prohibitively difficult to predict the actors (especially consumers) involving in the ties, and to set up boundary to such network. (See Christina Prell, supra note 8, at 118-119).

${ }^{40}$ A concept mentions by Patrik Wikstrom named as 'media presence'. In a complete graph, although every actor can connect with each other in accessing, sharing, and disseminating music, the abundancy of music flowed in the network, even though diverse, may not always be beneficial for the media presence of such music to the audience or consumers.

41 The hub actor being 'neutral' is important to enhance the diversity of music distributed and disseminated.

${ }^{42}$ In the 'star' graph, the centralized (hub) actor tend to have high degree of ties to others. The degree is seen as a measure for an actor's level of involvement or activity in the network. In such communication network, an actor with high degree of of centrality is one who can be considered to be a major channel for information in that particular network. This actor speaks with many others and thus both hears and spreads new information quickly. (Christina Prell, supra note 8, at 97). Such centralized (hub) actor can facilitate the enhancement of media presence of the music flowed in the network.
} 


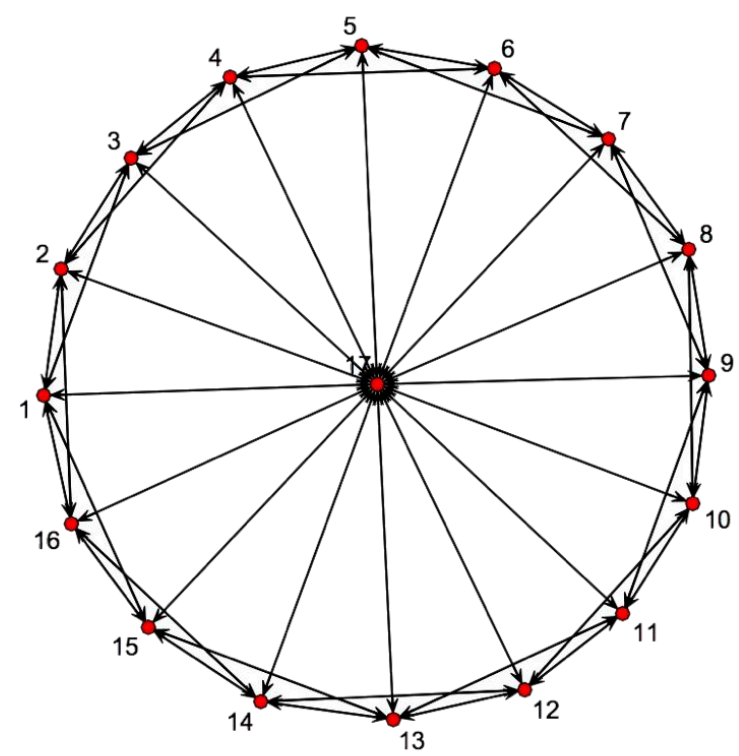

Figure 15. Simulation of a 'cloud' network

Examples to this cloud network is the networking through the Internet and the emerging neutral innovative Internet intermediary sites (as hub actors) which facilitate establishment of connections between the artists and consumers, including also the social networking sites with further features of music sharing between the consumers. One of the possible examples could be Youtube: it is a user-generated contents site which neutrally intermediates distribution and dissemination not only of diverse music products, but also other related videos, i.e. interview or live shows, of the artists' music. The users of Youtube can also connect to each other through commentary board of the video, and share any related video as a respond to the featuring video, visible to the other users and viewers. In this respect, consumers could have diverse access to music, both from the channels provided by the neutral Internet intermediaries, as well as from other consumers sharing the music and information through the Internet. In this way, consumers could discover more alternative music, including ways of enjoying music.

\section{Ramifications to The Copyright System}

In a conventional music business structure, the major source of income is guaranteed by the exclusive character of copyright. As a legal tool, copyright enables the actors having authorizations to reproduce or distribute music to the consumers to condition an 'artificial scarcity'. The gatekeepers, such as record labels, music distributors, or broadcasting organizations could select and control what music or which artists they want to promote, distribute, and disseminate to the public. Such oligopolistic structure of distribution and 
dissemination system is represented as a 'star' network where the paths to access the music are limited only to those provided by the exclusive hub actors.

The Internet and cloud computing technology have enabled easier flow of music between the consumers. These new technologies also resulted in a situation where the oligopolistic intermediary actors and gatekeepers of the conventional music business model are gradually losing their exclusive control over the distribution and dissemination of music among the consumers. Hence, the music can be accessed and disseminated by any user or consumer through the Internet and cloud, even though they do not have the authorization to do so; something that, according to the traditional copyright could be considered as a violation of exclusive rights of the right holders.

Nevertheless, the enforcement of copyright's exclusivity becomes costly partly because of prohibitive transaction costs in authorizing and licensing the rights to all of the users and consumers who have done, or have the potentials to distribute and disseminate the music in the Internet and cloud. Rather than depending on the exclusivity, the intermediaries in the music distribution and dissemination networks have started to design business models where consumers can be induced to pay for the access and enjoyment of music. Various subscription-based services with added features (e.g., recommended music or connection to the artists channel/playlist in reasonable fee ${ }^{43}$ ) have emerged. For intermediaries, such business models assures additional source of income. On the other hand, compared to the conventional music distribution models, Internet- and cloud-based business models must be supported by additional services, because consumers may not be willing to pay for simply basic access to the music.

Online music intermediaries providing innovative music features and services through the Internet and cloud have played essential role in changing consumer behavior as well as facilitating strategic use of the Internet and cloud for wide distribution of music. A combination of a 'star' network with neutral hub actor in the cloud network represents this case. The intervention of copyright, through enforcement of exclusivity to the hub actors in a cloud network, could disturb its neutrality as well as its facilitation of achieving a complete graph network for diverse music's distribution and dissemination to the consumers. In this respect, strong copyright enforcement will hinder the goal of music diversity and the development of innovative hub actors in the Internet and cloud.

The enforcement of copyright will induce such innovative hub actors to select and control the music distributed and disseminated, thereby making them similar as the conventional 'gatekeepers', where music will be less diverse, and the paths for artists to connect with consumers, as well as for consumers to access the music, will be much limited. In this respect, the social network analysis of music distribution and access helps explaining that enforcement of copyright protection conferring exclusive rights to the intermediaries are becoming more obsolete, especially when it relates to the the goal of achieving much diverse music distributed widely, as well as strategic and effective use of innovative Internet intermediaries in reducing distance and cost for music distribution and dissemination.

${ }^{43}$ Some of the examples: Distro.fm, which allows consumers to connect with the artists' music network; Last.fm, which provides the consumers with application to search for music and musicians worldwide; also MP3Tunes, which exists as the cloud music service, where it lets consumers store their own music in the "cloud," as well as allowing them to store and manage links to the streaming music found online. 
Changing business model as affected by the Internet and cloud (as in the case of Youtube $e^{44}$ ) has shown such indication; that the copyright has gradually lost the power to incentivize the business. Rather, such copyright protection could be substituted by a global silent contract where 'everyone can pay for everyone'.

\section{Conclusion}

The Internet and cloud computing have had a impact to the way of interaction between individuals. In fact, individual actors have been quickly adjusting the ways of operation to the possibilities provided by new technologies. The change in law as a tool of maintaining balance of interests between various stakeholders has not been as swift however. In this paper we analyse how the operation of music industry has been affected by the emergence of these novel Internet and cloud technologies. More particularly, our objective has been to assess the legal implications of such technological development to the copyright system.

In order to identify key characteristics of the music distribution and dissemination models we applied the so called 'social network' approach. This social network approach helps not only to identify the main stakeholders in the music industry, but also provides for palpable tools to explain the inter-relationship between the actors as well as the incentives for certain behaviour. The technological impact of the Internet and cloud computing to the music industry is further explained by juxtaposing two music distribution and dissemination business models: to so-called 'conventional' and Internet/cloud technology-based music distribution model. This comparison helped to single out the deficiencies of the 'conventional' music distribution model; namely, the situation where intermediaries capture the music distribution channels by means of exclusive copyrights. This has been illustrated by a 'star' network where intermediaries are able to control the content of what is distributed.

The social network approach also serves as a source for further considerations with regard to the adjustment of copyright system to the needs of the Internet and cloud-based communication networks. More particularly, as it was illustrated above, the role of intermediaries in the Internet and cloud-based networks is if a paramount significance in providing shortcuts between various actors. The existence of intermediaries is also vital because they help reduce transaction costs in distributing and disseminating music. However, in terms of the diversity of music distributed, we emphasise the need to make sure that the neutrality of intermediaries is maintained.

We further observe the fact that business models, technology and consumer attitudes make the exclusive power of copyright obsolete and that in the context of the Internet and cloud computing it is not possible to maintain the illusion of strong copyright. The Internet and

\footnotetext{
${ }^{44}$ Providing an example, when music video is streamed freely through Youtube, the site are sponsored by the advertising companies who place their ads in the page where music video is streamed. Youtube then could get 'service fee' of mediating the ads, in which the musicians could also shared their portions of revenue. In this case, the Internet intermediary (or, hub actor, i.e., Youtube) of the communication network is neutral and does not choose contents arbitrarily, and thereby has the potential to promote the diversity of music distributed, while being not incentivized by the exclusive power of copyright. Such conditions indicate that the intermediaries could be much neutral, considering they do not have to enforce any exclusivity of music flows from the gatekeepers. In this respect, the innovative Internet intermediaries as the neutral bridge in shortening the distance between the artists and consumers play essential role in facilitating the music distribution access in this Internet and cloud era.
} 
cloud computing technology have influenced the way the music industry's actors distribute and disseminate their music, and this includes the changes in consumers behaviors in accessing and enjoying the music. The essential issue is more on how to contsruct the distribution system where consumers are willing to pay, no longer on excluding other competitors, as copyright usual serves. This parallel with the importance to construct the Internet and cloud-based networks with neutral intermediaries in achieving a diverse distribute music, in which no/less intervention from the copyright may realize an effective music distribution system in this Internet and cloud computing era. 


\section{Bibliography}

\section{Books}

Borg, Bobby. 2003. The Musician's Handbook, A Practical Guide to understanding the Music Business. New York: Billboard Books.

Burt, R. S. 1988. Structural Holes: The Social Structure of Competition. Cambridge: Harvard University Press.

Caves, Richard E. 2000. Creative Industries-Contracts Between Art and Commerce. Cambridge: Harvard University Press.

Gammons, Helen. 2011. The Art of Music Publishing-An Enterpreneurial Guide to Publishing and Copyright for the Music, Film, and Media Industries. London: Elsevier Ltd.

Passman, Donald S. 2009. All You Need to Know About the Music Business - Revised and Updated. New York: Free Press.

Prell, Christina. 2012. Social Network Analysis: History, Theory, and Methodology. Los Angeles: Sage.

Scott, John. 2000. Social Network Analysis, a Handbook (second edition). London: Sage Publications Ltd.

Wikstrom, Patrik. 2009. The Music Industry, Digital Media and Society Series. Cambridge: Polity.

\section{Journal Papers}

Freeman, L. C., Centrality in Social Networks - Conceptual Clarification, Social Networks 1978/79, 1:215-239. 
Teramoto, S., Protect Network Neutrality against Intellectual Property Rights - A Legal and Social Network Perspective, International Proceedings of Economics Development and Research, 42: 7-11.

Watts, D. J. and S. H. Strogatz, Collective Dynamics of "Small-World" Network, Nature 1998, 393: 440-442. 